\title{
The Effect of Sound and Vibration on Postural Balance in Healthy Young Adults
}

\author{
Sunee BOVONSUNTHONCHAI", Pichaya HENGSOMBOON, \\ Sitapa TANGLUANG, Pran ANUSRI, \\ Pavitta CHOTIKUL and Warakorn PHIWMOU
}

Faculty of Physical Therapy, Mahidol University, Nakhon Pathom 73170, Thailand

('Corresponding author's e-mail: sunee.bov@mahidol.edu)

Received: 6 May 2018, Revised: 31 October 2018, Accepted: 8 November 2018

\begin{abstract}
Postural balance is influenced by alteration of somatosensory inputs. Sound and vibratory senses, one of several human senses may assist the postural control in a specific impaired situation. The aim of this pilot study was to quantify the effect of sound and vibration on postural balance in healthy young adults. Ten healthy young subjects volunteered to participate in the study. The average age, weight, height, and body mass index were $21.88 \pm 0.42$ years, $56.21 \pm 9.80 \mathrm{~kg}, 159.75 \pm 5.20 \mathrm{~cm}$, and $21.99 \pm$ $3.52 \mathrm{~kg} / \mathrm{m}^{2}$. They were assessed for standing postural balance on a force plate over 6 conditions of sound and vibration applications under vision was excluded by using a blindfold. Postural balance variables consisted of planar deviation of Center of Pressure $(\mathrm{CoP})$ and the maximum ranges of CoP in the mediolateral (ML) and antero-posterior (AP) directions. Two-way ANOVA was used to find the effect and interaction effect of sound and vibration on the postural balance variables. Further analyses of the variables were performed on a basis of each factor. Between sound conditions (no sound and open sound), the variables were analyzed by the paired $t$-test. In addition, the effect of vibration (no vibration, vibration on quadriceps, and vibration on gastrocnemius) on the variables were analyzed by the one-way repeated measure ANOVA. Results demonstrated no interaction effect and main effect of sound and vibration on the postural balance variables $(p>0.05)$. In addtion, no significant difference of the postural balance variables between sound conditions $(p>0.05)$ as well as among vibration conditions $(p>0.05)$. In conclusion, sound and vibration did not effect to the postural balance during standing in healty young adults.
\end{abstract}

Keywords: Center of pressure, postural balance, sound, vibration

\section{Introduction}

Postural balance is an important ability for maintaining posture and encourage locomotion in daily activities. Normal postural balance requires feedback information from the 3 main sensory systems including visual, vestibular, and somatosensory systems [1]. The visual system provides spatial information including location and movement of surrounding objects as well as movement of the body from retinal slip information [2,3]. The vestibular system provides linear and angular motion of head with respect to gravity and inertia [4-7]. The somatosensory system includes skin, muscles, and joint senses providing the position and movement of body segments [8-10]. This information is then used for determination of the bodily state in relation to the surrounding environment by the central nervous system (CNS) to generate or respond with the appropriate motor command to maintain a stable postural balance [11-13]. 
http://wjst.wu.ac.th

Inadequate sensory feedback systems can cause postural instability or an increase in postural sway. To maintain balance and minimize postural sway, the CNS has to select the information from the available senses and reduce dependency on the unavailable sense. This re-adjustment of weighting on sensory systems is called the "sensory reweighting" mechanism $[1,14]$. For instance, during standing with eyes closed condition that has no feedback information from visual system, the CNS has to use feedback information from the vestibular and somatosensory systems to estimate the state of the body with respect to the surrounding environment for generating proper motor commands to maintain a stable standing posture $[1,14]$. If information from the remaining feedback systems are sufficient, none or small amounts of postural sway will be found. Conversely, if the remaining feedback is insufficient, the postural sway will be prominent and loss of balance can occur.

Besides the 3 main sensory systems, previous studies have reported the contribution of the auditory system for maintaining postural balance [15-19]. A study by Kanegaonkar et al. in 2012 [17], reported the importance of the auditory system in maintaining postural control, showing that reduced auditory input resulted in an increase in postural sway. The auditory role for postural balance was observed especially when the visual system was unavailable [15,18]. Easton et al. [15], found that the blind participants used the auditory system to maintain bodily balance and planned the movement by estimating the location and direction of surrounding objects from the auditory system. Zhong and Yost in 2013 [18], reported the benefit of the auditory system for minimizing body sway in both static and dynamic balance tasks with eyes closed. They found a $9 \%$ reduction of mean postural sway for tandem stance test and $76 \%$ reduction of mean postural sway for the Fukuda stepping test when they provided a wide band noise sound from single static sound source to the participants [18]. The benefit of sound is also present during with visual feedback by using the auditory white noise on balance in healthy young adults [19]. In addition, the benefit of auditory input on postural balance can be found when the vestibular system is unavailable as in individuals with vestibular loss [16].

According to the aforementioned studies, a possible mechanism for the auditory system on standing postural balance is providing spatial location and the motion of surrounding objects via the sound [15-19]. It could be used as an augmented feedback for building the frame of reference to maintain bodily balance when visual [15,17-19] or vestibular [16] feedbacks are insufficient. However, little is known about the auditory role on postural balance when the proprioceptive sense is disturbed or unreliable. There are several methods for disturbing the proprioceptive sense such as application of cuff compression [20,21], cold [22,23], local anesthetic injection [24], and vibration on the belly muscles or tendons [12,25-29]. Vibration is a technique that is usually used because it is safe and applicable to several bodily parts. In addition, quadriceps and gastrocnemius muscles are important lower extremity muscles that play a role in maintaining balance. Thus, this study selected these muscles for the location of vibration in disturbing the sense. To obtain a more complete understanding of the sensory reweighting mechanism and auditory role on postural balance, this study aimed to investigate the interaction effect and main effect of sound and vibration on the standing postural balance. Further comparisons were performed between sound conditions and among vibration conditions. We hypothesized that a decrease in postural sway may appear when applying the sound during disturbance of the proprioceptive sense.

\section{Materials and methods}

\section{Participants}

Demographic data of the participants are shown in Table 1. Ten healthy volunteers who were 2 males and eight females participated in the study. Their averaged age, weight, and height were $21.88 \pm$ 0.42 years, $56.21 \pm 9.80 \mathrm{~kg}$, and $159.75 \pm 5.20 \mathrm{~cm}$. Participants were excluded if they had history of hearing or postural balance problems, vertigo or dizziness, visual problems which cannot be corrected by glasses or contact lens, impaired cutaneous sensation or joint proprioception, and musculoskeletal constraints such as pain at the spine or lower extremity. 
http://wjst.wu.ac.th

Table 1 Characteristic of the participants $(n=10)$.

\begin{tabular}{lc}
\hline Variables & Values (Mean \pm SD or counted number) \\
\hline Age (years) & $21.88 \pm 0.42$ \\
Gender (number) & Male $=2$ \\
& Female $=8$ \\
Weight $(\mathrm{kg})$ & $56.21 \pm 9.80$ \\
Height $(\mathrm{cm})$ & $159.75 \pm 5.20$ \\
Body mass index $\left(\mathrm{kg} / \mathrm{m}^{2}\right)$ & $21.99 \pm 3.52$ \\
Leg Length $(\mathrm{cm})$ & \\
$\quad$ Right & $82.55 \pm 2.63$ \\
$\quad$ Left & $82.75 \pm 2.88$ \\
\hline
\end{tabular}

\section{Postural balance variables}

Postural balance was assessed in the standing position determined by the Center of Pressure (CoP) variables, including the planar deviation, maximum ranges of $\mathrm{CoP}$ along the medio-lateral (ML) and the antero-posterior (AP) directions (Table 2) [30]. All CoP variables were recorded by using a single force plate (AMTI forceplate, model OR6-7). The force data were collected at a sampling frequency of 1000 $\mathrm{Hz}$. In analysis, the force data were filtered with the low pass fourth order Butterworth technique at a cut off frequency of $40 \mathrm{~Hz}$.

Table 2 Formula and description of the variables.

\begin{tabular}{lcc}
\hline \multicolumn{1}{c}{ Variables } & Description & Unit \\
\hline Planar deviation & $\sqrt{\left(\sigma^{2} \mathrm{x}+\sigma^{2} \mathrm{y}\right)}$ & $\mathrm{mm}$ \\
Range of CoP in the ML & $\left|x_{\max }-x_{\min }\right|$ & $\mathrm{mm}$ \\
Range of CoP in the AP & $\left|y_{\max }-y_{\min }\right|$ & $\mathrm{mm}$ \\
\hline
\end{tabular}

Note: $\mathrm{x}$, data in $\mathrm{x}$-axis or in the medio-lateral direction; $\mathrm{y}$, data in $\mathrm{y}$-axis or in the antero-posterior direction; $\sigma^{2}$, squared estimated standard deviation.

\section{Instrument and equipment for testing}

An industrial ear muff which could reduce sound intensity up to 30 decibel (dB) was used to reduce ambient sound in the testing room for the no-sound condition. Because postural control primarily based on vision. This study used a bind fold to reduce the influence of vision in all testing conditions. During testing in the auditory condition, the wide-band white noise sound $(20-20,000 \mathrm{~Hz})$ with $65 \mathrm{~dB}$ of intensity was lunched from 2 audio speakers to generate static reference points for improve standing balance. The white noise sound was generated by the sound generator software. Two audio speakers were placed at the level of the participant's ears 1 meter apart from each ear. Four customized vibrators with $150 \mathrm{~Hz}$ of frequency [31] were applied to interrupt the proprioceptive sensation of the lower extremities. Vibrators were synchronized and triggered by a single switch for vibrate the muscles. For all testing conditions with muscle vibration, $60 \mathrm{sec}$ of data collection were separated into 3 phases, including prior vibration ( 0 to $20 \mathrm{sec})$, vibration $(20.001$ to $40 \mathrm{sec})$, and post vibration $(40.001$ to $60 \mathrm{sec})$. 
http://wjst.wu.ac.th

\section{Procedure}

At the beginning, all participants received details and procedures of the study. They signed the informed consent approved by the institutional ethic committee (MU-CIRB 2016/046.0704). Then, demographic data and screening tests were performed. Four vibrators were placed on the left and right quadriceps and gastrocnemius muscles.

Before the testing began, participants were asked to stand with feet together at center of the force plate. Their feet placement location was marked for the same foot placement of all testing conditions. In no sound conditions, they were asked to wear industrial ear muffs to prevent sound. In addition, a blind fold was applied to limit visual information for all testing conditions. The testing sequence was random by draw lot method to prevent the learning effect of the participants. All participants were allowed to practice once to familiarize themselves with the testing method. Six testing conditions are described in Table 3.

Table 3 Testing conditions of the study.

\begin{tabular}{lll}
\hline Condition & Auditory & Proprioception \\
\hline 1 & No sound & No vibration \\
2 & Open sound & No vibration \\
3 & No sound & Vibration on quadriceps muscle \\
4 & Open sound & Vibration on quadriceps muscle \\
5 & No sound & Vibration on gastrosoleus muscle \\
6 & Open sound & Vibration on gastrosoleus muscle \\
\hline
\end{tabular}

After complete preparation, participants were asked to stand as still as possible for $60 \mathrm{sec}$. Each testing condition was collected for 3 times. To avoid muscle fatigue, they were allowed to rest approximately $1 \mathrm{~min}$ or until ready to be tested in the next testing conditions. Averaged values from 2 successful trials of each condition were used for statistical analysis.

For the testing condition with vibration, vibrators were turned on at $20 \mathrm{sec}$ and turned off at $40 \mathrm{sec}$. Data from 2.501 to $17.500 \mathrm{sec}$ were selected to represent prior vibrated data. The data from 22.501 to $37.500 \mathrm{sec}$ represented data within the vibrating period. The data from 42.501 to $57.500 \mathrm{sec}$ represented the post-vibrated data.

\section{Sample size calculation}

The $\mathrm{G}^{*}$ Power program version 3.1.9.2 was used to quantify a priori sample size calculation for this study. Based on the findings of Capicikova et al. in 2006 [32] who investigated the effect of vibration on soleus muscle on the CoP sway amplitude and velocity in the ML direction during standing. Their findings demonstrated the $\mathrm{CoP}$ amplitudes before and after vibration application were $10 \pm 2 \mathrm{~mm}$ and 15 $\pm 3 \mathrm{~mm}$, respectively. The alpha error probability of 0.05 and power of 0.95 were set in the calculation process and the number of participants was 6 . Thus, a total number of 10 participants is expected to suitable for this study.

\section{Data analyses}

Normality of all parameters were determined by the Kolmogorov Smirnov Goodness of Fit Test and represented with a normal distribution. The interaction effect and main effect of sound (no sound and open sound) and vibration (no vibration, vibration on the quadriceps, and vibration on the gastrocnemius) factors on the postural control variables were analyzed by the 2 way ANOVA.

Because the 2-way ANOVA is based on the grand mean analysis, further analyses of the mean differences of the postural control variables were separately performed in each condition. Between sound conditions (no sound and open sound), the variables were analyzed by the paired $t$-test. In addition, the 
http://wjst.wu.ac.th

effect of vibration (no vibration, vibration on quadriceps, and vibration on gastrocnemius) on variables were analyzed by the one-way repeated measure ANOVA. The significance level of statistical analyses was set at $\mathrm{p}<0.05$ for all comparisons.

\section{Results and discussion}

\section{Interaction effect and main effect of sound and vibration}

The interaction effect and main effect of 2 factors, sound (no sound and open sound) and vibration (no vibration, vibration on the quadriceps, and vibration on the gastrocnemius) were analyzed by using the 2 way ANOVA. For the planar deviation of $\mathrm{CoP}$, there was no interaction effect of sound and vibration $[F(2,54)=0.092, p=0.912]$ as well as no main effect of sound $[F(1,54)=0.002, p=0.963]$ or vibration $[\mathrm{F}(2,54)=0.379, \mathrm{p}=0.687]$ on this variable. For the range of CoP in ML, there was no interaction effect of sound*vibration $[\mathrm{F}(2,54)=0.095, \mathrm{p}=0.909]$ and no main effect of sound $[\mathrm{F}(1,54)$ $=0.209, \mathrm{p}=0.649]$ or vibration $[\mathrm{F}(2,54)=0.748, \mathrm{p}=0.478]$ was found. For the range of CoP in AP, there was no interaction effect of sound*vibration $[\mathrm{F}(2,54)=0.067, \mathrm{p}=0.936]$ and no main effect of sound $[F(1,54)=0.008, p=0.931]$ or vibration $[F(2,54)=0.288, p=0.751]$ was found.

\section{Effect of sound on postural balance variables in different conditions of vibration}

Table 4 presents a comparison of the postural balance variables between no sound and open sound in different conditions of vibration. There was no significant effect of sound on all postural balance variables $(\mathrm{p}>0.05)$.

Table 4 Comparisons of no sound and open sound on the postural balance variables in different conditions of vibration.

\begin{tabular}{llccc}
\hline \multicolumn{1}{c}{ Conditions } & \multicolumn{1}{c}{ Variables } & $\begin{array}{c}\text { No sound } \\
\text { (Mean } \pm \text { SD) }\end{array}$ & $\begin{array}{c}\text { Open sound } \\
\text { (Mean } \pm \text { SD) }\end{array}$ & p-value* $^{\text {No vibration }}$ \\
& Planar deviation of CoP & $6.70 \pm 1.98$ & $6.38 \pm 1.54$ & 0.606 \\
& Range of CoP in ML & $24.21 \pm 7.59$ & $23.06 \pm 6.15$ & 0.532 \\
& Range of CoP in AP & $21.44 \pm 6.38$ & $20.98 \pm 6.42$ & 0.661 \\
Vibration on the & Planar deviation of CoP & $6.13 \pm 1.63$ & $6.03 \pm 1.85$ & 0.844 \\
quadriceps & Range of CoP in ML & $20.81 \pm 6.57$ & $21.69 \pm 6.40$ & 0.508 \\
& Range of CoP in AP & $18.49 \pm 6.03$ & $20.15 \pm 5.22$ & 0.326 \\
Vibration on the & Planar deviation of CoP & $6.57 \pm 2.05$ & $6.52 \pm 1.53$ & 0.932 \\
gastrocnemius & Range of CoP in ML & $23.93 \pm 6.38$ & $24.76 \pm 6.71$ & 0.624 \\
& Range of CoP in AP & $19.91 \pm 6.28$ & $20.28 \pm 6.76$ & 0.792 \\
\hline
\end{tabular}

*Significant difference tested by the paired $t$-test at $\mathrm{p}<0.05$

During no vibration on the lower extremity muscles, there was no significant effect of sound to reduce the postural balance variables in this study. This finding is contrary with the previous reports that showed the benefit of sound on postural balance when vision was unavailable [15-19]. The reasons for this issue may relate to several possible factors. The factor may be mainly influenced by the age of the participants tested in the study. All participants were young adults who had the mean age of $21.88 \pm 0.42$ years. Previous evidence reported that postural balance was more easily disturbed in the elderly than the young [33-36]. The elderly exhibited lower postural steadiness during standing than the young. This is represented in terms of the larger CoP displacement and velocity and the larger center of mass $(\mathrm{CoM})$ displacement and acceleration [33-36]. With a stronger musculoskeletal system and ability of neural control, young adults may have more adaptive function of sensory systems for maintaining postural 
http://wjst.wu.ac.th

balance against surrounding disturbance factors [36-38]. Even though the vision was excluded, the ability to maintain balance of young adults may depend on vestibular and/or proprioceptive sense rather than relying on the auditory system.

For young adults, it may be easier to capture the response with kinematics of the upper bodily segments than the postural sway variable on the ground. Previous studies have shown that the bilateral vibrations at the Achilles tendon induce a backward sway, captured by an increase in the trunk and hip angles in the young adults [39].

Another possible reason may involve attention or cognitive load of the sound. The study of Deviterne et al. in 2005 [40] found that the sound with cognitive load had greater effect on postural balance than the sound without cognitive load. However, the present study used white noise sound without cognitive load for improving the postural balance. Thus, if participants focused only on the standing task and did not attend to the sound, it may be difficult to see the effect of sound on postural balance task obviously.

\section{Effect of vibration on postural balance variables in no sound condition}

As present in Table 5, in the no sound condition, there was no significant difference of the planar deviation of $\operatorname{CoP}[\mathrm{F}(2,18)=0.584, \mathrm{p}=0.568]$ range of $\mathrm{CoP}$ in $\mathrm{ML}[\mathrm{F}(2,18)=2.953, \mathrm{p}=0.078]$, and range of $\mathrm{CoP}$ in $\mathrm{AP}[\mathrm{F}(2,18)=2.268, \mathrm{p}=0.132]$ among no vibration, vibration on the quadriceps, and vibration on the gastrocnemius.

Table 5 Comparisons of vibration conditions on the postural balance variables in no sound condition.

\begin{tabular}{|c|c|c|c|c|c|c|}
\hline \multirow[b]{2}{*}{ Variables } & \multicolumn{3}{|c|}{ Conditions } & \multirow[b]{2}{*}{$\mathbf{F}$} & \multirow[b]{2}{*}{ df } & \multirow[b]{2}{*}{ p-value* } \\
\hline & No vibration & $\begin{array}{l}\text { Vibration on } \\
\text { the quadriceps }\end{array}$ & $\begin{array}{l}\text { Vibration on the } \\
\text { gastrocnemius }\end{array}$ & & & \\
\hline Planar deviation of CoP & $6.70 \pm 1.98$ & $6.13 \pm 1.63$ & $6.57 \pm 2.05$ & 0.584 & 2 & 0.568 \\
\hline Range of CoP in ML & $24.21 \pm 7.59$ & $20.81 \pm 6.57$ & $23.93 \pm 6.38$ & 2.953 & 2 & 0.078 \\
\hline Range of CoP in AP & $21.44 \pm 6.38$ & $18.49 \pm 6.03$ & $19.91 \pm 6.28$ & 2.268 & 2 & 0.132 \\
\hline
\end{tabular}

*Significant difference tested by the one way repeated measure ANOVA test at $\mathrm{p}<0.05$.

The results of vibration on quadriceps and gastronemius muscles did not support our expectation that vibration will increase postural sway as in previous reports [41,42]. They demonstrated the vibration on gastronemius muscles could increase CoP sway along the AP direction [41,42]. The failure to observe the changes of CoP in present study might be explained by the difference of vibration frequency. The vibration frequency in present study was around $150 \mathrm{~Hz}$, while some previous studies used between 60 to $100 \mathrm{~Hz}$ [41-43]. Therefore, a vibration frquency of $150 \mathrm{~Hz}$ may be less effective to stimulate muscle spindle and induce postural sway. Another reason might relate to the area of the vibrator attached. The studies that placed a vibrator on the archilles tendon instead of the muscles to disrupt proprioceptive cue from the ankle and found the backwad sway [31] or the increase in the COP displacement and angular displacement of hip, knee, and ankle joints [43].

However, controversial findings were reported in a previous study that did not find the effect of vibration on postural balance when disrupted by the sensation of a vibrator at the quadriceps muscles [29]. The underlying reason was related to young adults using a mechnaism of ankle strategy to maintain standing posture during the disturbance.

The ability to reweigh sensory mechanis or adapt to stimulation while some systems are unavaiable for the optimal postural balance control in young adults can be confirmed by neuroimaging studies. Several brain areas contain multimodal neurons that respond to different types of sensory stimuli or situations during standing. Ouchi et al. in 1999 [44] used the positron emission tomography to investigate 
http://wjst.wu.ac.th

hemodynamic response following bipedal or unipedal stand with eyes open or closed. The findings demonstrate an increased activation of the cerebellar anterior vermis and posterior lobe lateral cortex during unipedal stand and increased activation of the cerebellar anterior lobe and right visual cortex during bipedal stand. By using near-infrared spectroscopy, during the perturbation in the ML direction, activation of prefrontal and dorsolateral prefrontal cortexes was accompanied with the increased activation of the right posterior parietal cortex and supplementary motor area under conditions with an auditory warning signal [45].

\section{Conclusions}

According to the results of this study, sound and vibration did not effect the postural balance during standing in healthy young adults. The study about the method to disturb balance in healthy young is needed for more clarification. In addition, the study may be limited by a small number of participants and generalizability of the population. Information of the effect of sound and vibration on postural balance for the ones who have impaired balance such as the elderly or other impaired individuals are required in a further study.

\section{Acknowledgements}

We would like to thank all individuals who participated in the study.

\section{References}

[1] RJ Peterka. Sensorimotor integration in human postural control. J. Neurophysiol. 2002; 88, 1097118.

[2] AE Patla. Understanding the roles of vision in the control of human locomotion. Gait Posture 1997; 5, 54-69.

[3] MS Redfern, L Yardley and AM Bronstein. Visual influences on balance. J. Anxiety Disord. 2001; 15, 81-94.

[4] JH Allum, AL Adkin, MG Carpenter, M Held-Ziolkowska, F Honegger and K Pierchala. Trunk sway measures of postural stability during clinical balance tests: Effects of a unilateral vestibular deficit. Gait Posture 2001; 14, 227-37.

[5] FB Horak. Postural compensation for vestibular loss and implications for rehabilitation. Restor. Neurol. Neurosci. 2010; 28, 57-68.

[6] CG Horlings, UM Kung, F Honegger, BG Van Engelen, NV Alfen, BR Bloem and JH Allum. Vestibular and proprioceptive influences on trunk movements during quiet standing. Neuroscience 2009; 161, 904-14.

[7] CF Runge, CL Shupert, FB Horak and FE Zajac. Role of vestibular information in initiation of rapid postural responses. Exp. Brain Res. 1998; 122, 403-12.

[8] HJ Kars, JM Hijmans, JH Geertzen and W Zijlstra. The effect of reduced somatosensation on standing balance: A systematic review. J. Diabetes Sci. Tech. 2009; 3, 931-43.

[9] C Maurer, T Mergner, B Bolha and F Hlavacka. Human balance control during cutaneous stimulation of the plantar soles. Neurosci. Lett. 2001; 302, 45-8.

[10] GG Simoneau, JS Ulbrecht, JA Derr and PR Cavanagh. Role of somatosensory input in the control of human posture. Gait Posture 1995; 3, 115-22.

[11] TM Dijkstra, G Schoner and CC Gielen. Temporal stability of the action-perception cycle for postural control in a moving visual environment. Exp. Brain Res. 1994; 97, 477-86.

[12] A Kavounoudias, JC Gilhodes, R Roll and JP Roll. From balance regulation to body orientation: Two goals for muscle proprioceptive information processing? Exp. Brain Res. 1999; 124, 80-8.

[13] AE Pavlik, JT Inglis, M Lauk, L Oddsson and JJ Collins. The effects of stochastic galvanic vestibular stimulation on human postural sway. Exp. Brain Res. 1999; 124, 273-80.

[14] RA Speers, AD Kuo and FB Horak. Contributions of altered sensation and feedback responses to changes in coordination of postural control due to aging. Gait Posture 2002; 16, 20-30. 
http://wjst.wu.ac.th

[15] RD Easton, AJ Greene, P DiZio and JR Lackner. Auditory cues for orientation and postural control in sighted and congenitally blind people. Exp. Brain Res. 1998; 118, 541-50.

[16] M Dozza, FB Horak and L Chiari. Auditory biofeedback substitutes for loss of sensory information in maintaining stance. Exp. Brain Res. 2007; 178, 37-48.

[17] RG Kanegaonkar, K Amin and M Clarke. The contribution of hearing to normal balance. $J$. Laryngol. Otol. 2012; 126, 984-8.

[18] X Zhong and WA Yost. Relationship between postural stability and spatial hearing. J. Am. Acad. Audiol. 2013; 24, 782-8.

[19] JM Ross and R Balasubramaniam. Auditory white noise reduces postural fluctuations even in the absence of vision. Exp. Brain Res. 2015; 233, 2357-63.

[20] KH Mauritz and V Dietz. Characteristics of postural instability induced by ischemic blocking of leg afferents. Exp. Brain Res. 1980; 38, 117-9.

[21] S Demura, S Yamaji, T Kitabayashi, T Yamada and M Uchiyama. Attention of postural control on foot somatosensor disturbance caused by the compression of blood vessels. J. Hum. Ergol. 2008; 37, 91-102.

[22] F Stal, PA Fransson, M Magnusson and M Karlberg. Effects of hypothermic anesthesia of the feet on vibration-induced body sway and adaptation. J. Vestib. Res. 2003; 13, 39-52.

[23] K Fujiwara, H Asai, A Miyaguchi, H Toyama, K Kunita and K Inoue. Perceived standing position after reduction of foot-pressure sensation by cooling the sole. Percept. Mot. Skills 2003; 96, 381-99.

[24] H Kjaergard, T Korsgaard Larsen, PS Rasmussen and L Brondum. Impairment of postural stability following perivascular axillary block with mepivacaine. Acta Anaesthesiol. Scand. 1984; 28, 50810 .

[25] C Thompson, M Belanger and J Fung. Effects of plantar cutaneo-muscular and tendon vibration on posture and balance during quiet and perturbed stance. Hum. Mov. Sci. 2011; 30, 153-71.

[26] H Ceyte, C Cian, R Zory, PA Barraud, A Roux and M Guerraz. Effect of Achilles tendon vibration on postural orientation. Neurosci. Lett. 2007; 416, 71-5.

[27] G Barbieri, AS Gissot, F Fouque, JM Casillas, T Pozzo and D Perennou. Does proprioception contribute to the sense of verticality? Exp. Brain Res. 2008; 185, 545-52.

[28] C Thompson, M Belanger and J Fung. Effects of bilateral Achilles tendon vibration on postural orientation and balance during standing. Clin. Neurophysiol. 2007; 118, 2456-67.

[29] CJ Shanahan, TV Wrigley, MJ Farrell, KL Bennell and PW Hodges. Postural response to vibration of triceps surae, but not quadriceps muscles, differs between people with and without knee osteoarthritis. J. Orthop. Res. 2014; 32, 989-96.

[30] JA Raymakers, MM Samson and HJ Verhaar. The assessment of body sway and the choice of the stability parameter(s). Gait Posture 2005; 21, 48-58.

[31] G Eklund. General features of vibration-induced effects on balance. Ups. J. Med. Sci. 1972; 77, $112-24$

[32] N Capicikova, L Rocchi, F Hlavacka, L Chiari and A Cappello. Human postural response to lower leg muscle vibration of different duration. Physiol. Res. 2006; 55, S129-34.

[33] K Masani, AH Vette, M Kouzaki, H Kanehisa, T Fukunaga and MR Popovic. Larger center of pressure minus center of gravity in the elderly induces larger body acceleration during quiet standing. Neurosci. Lett. 2007; 422, 202-6.

[34] TE Prieto, JB Myklebust, RG Hoffmann, EG Lovett and BM Myklebust. Measures of postural steadiness: Differences between healthy young and elderly adults. IEEE Trans. Biomed. Eng. 1996; 43, 956-66.

[35] E Yu, M Abe, K Masani, N Kawashima, F Eto, N Haga and K Nakazawa. Evaluation of postural control in quiet standing using center of mass acceleration: Comparison among the young, the elderly, and people with stroke. Arch. Phys. Med. Rehabil. 2008; 89, 1133-9.

[36] T Tanaka, S Kojima, H Takeda, S Ino and T Ifukube. The influence of moving auditory stimuli on standing balance in healthy young adults and the elderly. Ergonomics 2001; 44, 1403-12. 
http://wjst.wu.ac.th

[37] AH Vette, DG Sayenko, M Jones, MO Abe, K Nakazawa and K Masani. Ankle muscle cocontractions during quiet standing are associated with decreased postural steadiness in the elderly. Gait Posture 2017; 55, 31-6.

[38] EJ Bisson, Y Lajoie and M Bilodeau. The influence of age and surface compliance on changes in postural control and attention due to ankle neuromuscular fatigue. Exp. Brain Res. 2014; 232, 83745.

[39] D Abrahamova, M Mancini, F Hlavacka and L Chiari. The age-related changes of trunk responses to achilles tendon vibration. Neurosci. Lett. 2009; 467, 220-4.

[40] D Deviterne, GC Gauchard, M Jamet, G Vancon and PP Perrin. Added cognitive load through rotary auditory stimulation can improve the quality of postural control in the elderly. Brain Res. Bull. 2005; 64, 487-92.

[41] NC Duclos, L Maynard, J Barthelemy and S Mesure. Postural stabilization during bilateral and unilateral vibration of ankle muscles in the sagittal and frontal planes. J. Neuro Eng. Rehabil. 2014; 11, 130

[42] A Polonyova and F Hlavacka. Human postural responses to different frequency vibrations of lower leg muscles. Physiol. Res. 2001; 50, 405-10.

[43] R Kabbaligere, BC Lee and CS Layne. Balancing sensory inputs: Sensory reweighting of ankle proprioception and vision during a bipedal posture task. Gait Posture 2017; 52, 244-50.

[44] Y Ouchi, H Okada, E Yoshikawa, S Nobezawa and M Futatsubashi. Brain activation during maintenance of standing postures in humans. Brain 1999; 122, 329-38.

[45] M Mihara, I Miyai, M Hatakenaka, K Kubota and S Sakoda. Role of the prefrontal cortex in human balance control. Neuroimage 2008; 43, 329-36. 